\title{
A TOMADA DA PALAVRA PARA ENSINAR E PARA ESCREVER
}

Resenha de:

NETTO, D. F. Produção Textual - formulando e reformulando práticas de sala. São Paulo: Paco Editorial, 2017. (186 p.)

\section{Raphaela Monteiro Chittolina ${ }^{1}$}

Durante muito tempo, pensar em produção textual no Ensino Médio significou apenas ensinar uma escrita que fosse adequada ao vestibular. Ainda hoje, muitas escolas ensinam texto para que os alunos passem no vestibular e não porque é preciso aprender a escrever. Esse quadro que atrela Ensino Médio e vestibular ainda se faz muito presente, visto que ainda existem diversas produções acadêmicas focadas nos relatos de problemas escolares e universitários acerca da questão do vestibular. Contudo, a contribuição de Paulo Coimbra Guedes e seu livro Da Redação à Produção Textual: o ensino da escrita (2009) é um grande passo para um ensino que proporcione uma aprendizagem mais variada quanto ao que é escrever um texto. Nessa obra, Guedes (2009) desconstrói a redação pensada para o vestibular e ensina aos alunos de Ensino Superior uma produção textual que não apenas reproduza um modelo aceito em instituições, mas que valha a leitura porque tem algo a dizer. $\mathrm{O}$ autor, assim, cria um método pedagógico a fim de uma escrita com mais sentido.

Para isso, Guedes (2009) apresenta as qualidades discursivas relacionadas à produção textual: unidade temática, questionamento, concretude e objetividade. De modo resumido, unidade temática é o assunto que será tratado no texto e que orienta o escritor a se manter dentro de um mesmo tema; questionamento é a bronca que o autor compartilha com o leitor, convocando-o a pensar, a se envolver e questionar aquilo que lê; concretude é o que o leitor necessita para que visualize mentalmente o que está lendo - qualidade que garante a precisão de sentido - e, por fim, objetividade é oferecer ao leitor o que ele necessita para entender o texto por meio do distanciamento daquilo que se escreve e colocando-se também no lugar de um leitor.

Com base na obra de Guedes (2009), Daniela Favero Netto, da Universidade Federal do Rio Grande do Sul (UFRGS), também propõe um ensino que se diferencie do repertório ainda comum na escola. Com sua tese de doutorado posteriormente também publicada em formato de livro, chamado Produção Textual - formulando e reformulando práticas de sala de aula (2017), Netto busca compreender se os estudos de Guedes (2009) contribuem para a melhora dos textos argumentativos de alunos do Ensino Médio. Para realizar essa análise, Netto propôs práticas de sala de aula voltadas ao ensino e à aprendizagem de textos argumentativos no Colégio de Aplicação da UFRGS (CAp).

Ao falar de sala de aula, é necessário esclarecer o que Netto entende por prática-pedagógica: oportunizar atividades com as quais o aluno seja capaz de refletir e produzir conhecimento (NETTO, 2017, p. 38). Assim, segundo Netto, o professor precisa analisar a proposta que levará para a aula, em uma via de mão dupla entre teoria e prática, a fim de uma atividade que promova a crítica, diferentemente da prática repetitiva. A metodologia de Netto é a pesquisa qualitativa interpretativa com foco na pesquisa-ação: refletir sobre uma situação, acionar uma prática e analisar quais foram os resultados dessa ação. Os dados da pesquisa que resultaram no livro de Netto se constituem de anotações sobre as práticas de sala de aula e vinte textos selecionados para analisar a presença ou a ausência das qualidades discursivas - qualidades que orientaram suas práticas de

\footnotetext{
${ }^{1}$ Mestranda em Linguística Aplicada pela Universidade Federal do Rio Grande do Sul (UFRGS). Contato: raphaelamonteiro@hotmail.com.
} 
sala de aula, além da relação identificada entre os estudos de Guedes e de Bakhtin² (2009), bem como a reflexão sobre o hábito de leitura pública de textos dentro de sala de aula.

Dito isso, a obra de Netto está dividida em quatro capítulos. O primeiro é um capítulo introdutório que serve como norte para que o leitor conheça um pouco sobre a autora, sobre a realidade de quem escreve e onde se situa essa pesquisa. A questão principal que motiva a obra também já é aqui apresentada. Tal questão, sendo assim, é a seguinte: qual a contribuição dos estudos de Guedes (2009) para a qualidade dos textos argumentativos de alunos do Ensino Médio, a partir do desenvolvimento das qualidades discursivas apontadas por Guedes (2009)? De acordo com Netto, o seu propósito, a partir dessa questão principal, é estabelecer um diálogo com professores-pesquisadores que refletem sobre a prática de sala de aula.

No segundo capítulo, Netto conta da sua vontade de trazer um projeto diferenciado aos alunos quando ainda era professora de uma antiga escola que não acolheu o seu projeto. Apenas ao chegar ao CAp é que se tornou possível colocar em prática a sua ideia engavetada: um projeto de debates entre alunos. Tal projeto se constitui em quatro grandes debates que foram realizados pelos alunos com a participação dos professores julgadores. Como atividade inicial para os debates, os alunos assistiram ao filme $O$ Grande Desafio ${ }^{3}$, no qual a temática principal é o poder das palavras focado no gênero debate. Netto explica, em seu livro, que essa primeira atividade tinha como objetivo apresentar aos alunos a dinâmica de funcionamento de um debate. Assim, no ano de 2012, foram realizados debates nas turmas de oitava série. Nesse capítulo, descobrimos a origem do questionamento que a levou à pesquisa: a recorrência de problemas, principalmente relacionados à interlocução, nos textos produzidos pelos alunos após a realização dos debates.

Materiais que conduzissem os alunos sobre como fazer um debate foram estudados pelos alunos e o tema do debate foi escolhido pensando no contexto escolar, apesar dos alunos, inicialmente, sugerirem temas já esperados - como a legalização do aborto, por exemplo. A autora, agindo como uma professora que se preocupa com o contexto escolar, direcionou os alunos a pensarem sobre questões que interessam mais ao local onde estão; assim, o tema central dos debates passou a ser o questionamento de haver ou não formatura nas oitavas séries de 2012 do CAp ${ }^{4}$. Cabe relatar que Netto conseguiu, durante demonstrações de como as discussões funcionam, a partir de filmes e de vídeos na internet, fazer os alunos estudarem a comparação, a concessão, a sustentação e a refutação de posicionamentos - como as analogias, as descrições, os relatos, as negociações de conflitos; além disso, os alunos também estudaram algumas marcas linguísticas da argumentação - como os recursos retóricos, os tempos verbais, as funções de tematização e rematização e os operadores argumentativos. Isso comprova que é possível ensinar texto por caminhos diferentes daqueles que disseminam apenas o ato de produzir macetes.

Os debates eram divididos, então, por um grupo a favor e outro grupo contra o tema proposto, e os alunos falavam com base em registros que haviam elaborado juntamente com seu grupo. A ação do debate foi uma prática apresentada de maneira minuciosa em seu livro; uma prática que, de fato, levou os alunos a aprenderem sobre argumentação oral e escrita. Conforme a autora, após o primeiro debate, um segundo tema foi sugerido pelo professor de História do CAp, porém tratouse de um assunto que não partiu dos próprios alunos e que, por isso, acabou não sendo muito proveitoso, deixando a conclusão de que os temas precisam partir das inquietações de quem debate ou escreve, isto é, do próprio autor, antes de tudo.

Responsabilizando-se pelas consequências da aprendizagem dos alunos em sala de aula, a autora assume que foi um erro, já no momento em que os alunos colocavam o debate em prática, pedir para que os alunos não utilizassem expressões coloquiais em suas falas (NETT'TO, 2017, p.

\footnotetext{
${ }^{2}$ Filósofo e pensador russo, grande pensador da linguagem humana e do gênero discursivo.

${ }^{3}$ Dirigido por Denzel Washington e lançado no ano de 2007. Resumidamente, a sinopse do filme conta com uma história inspirada em acontecimentos reais, tendo como protagonista um brilhante professor que utiliza métodos poucos convencionais para motivar seus alunos universitários a participar de um campeonato de debates.

4 As cerimônias de formatura das oitavas séries deixaram de existir desde 2008 em função de problemas disciplinares ocorridos durante a última cerimônia realizada.
} 
27), o que acabou gerando uma preocupação desnecessária da parte dos alunos com esse aspecto e desmotivando-os com relação ao aspecto mais importante: a construção da argumentação. Isso porque, como explica Netto, comumente os alunos utilizavam expressões semelhantes a gírias, tais como "tipo assim" e "tá ligado". Com esse pedido de Netto aos alunos, para que evitassem tais gírias, a autora constatou que os alunos acabaram trazendo argumentos pouco consistentes porque se preocupavam demasiadamente com a realização das concordâncias em suas frases e não com a própria argumentação.

Paremos aqui para refletir, por um momento, acerca do acontecido: o mesmo movimento que tirou o foco dos alunos, pois eles se preocupavam com a maneira como falariam ou escreveriam, é o movimento que também faz com que, refiro-me agora de modo geral, os alunos não produzam textos com sentido: os alunos se preocupam com uma estrutura exata e uma gramática impecável e, nessa preocupação, muitas vezes, esses alunos perdem a essência daquilo que escrevem. Aparentemente, os alunos anseiam desnecessariamente acertar questões que poderiam ser revisadas depois que a escrita realmente significativa acontece. Contudo, esta é uma reflexão minha a partir da leitura do livro, não é de Netto.

Já no terceiro capítulo, Netto explica a sua metodologia de pesquisa e o uso do trabalho de Guedes (2009) para a análise dos textos e as propostas pedagógicas em aula. A autora optou por utilizar apenas três das quatro qualidades discursivas: unidade temática, questionamento e concretude. $\mathrm{O}$ esforço empreendido pelos alunos de Ensino Médio em compreender todos os conceitos poderia estar acima do aprendizado acerca das produções textuais ${ }^{5}$. Por isso, a qualidade discursiva da objetividade, então, passou a ser analisada dentro da concretude. Assim, Netto explica cada uma das qualidades discursivas e o quanto elas são capazes de gerar um novo aprendizado textual. Ainda neste capítulo, Netto relaciona os estudos de Guedes (2009) à perspectiva dialógica de Bakhtin (2009), apresentando também outros estudos - como o de Bronckart ${ }^{6}$ (2012) e o de Charaudeau ${ }^{7}$ (2012) , por se tratarem de autores que seguem os pressupostos de Bakhtin (2009). A autora observa a opção de Guedes (2009) por não tratar de gêneros textuais e como o autor opta por uma abordagem que não parte do estudo de gêneros textuais. Porém, Netto percebe que o trabalho com as qualidades discursivas reflete uma abordagem cuja perspectiva é também a dos gêneros do discurso, o que, de maneira nenhuma é uma oposição à proposta de Guedes (2009), mas uma complementação.

As especificidades de uma abordagem que se insere no âmbito dos gêneros textuais e de uma que se insere no âmbito dos gêneros discursivos são apontadas pela autora neste terceiro capítulo. Ao final da comparação entre autores, Netto sintetiza suas diferenças e semelhanças teóricas: Bronckart (2012) e Charaudeau (2012), por um lado, refletem sobre a materialidade discursiva do texto sem uma intenção pedagógica de ensinar produções textuais. Guedes (2009), por outro lado, une suas reflexões ao ato pedagógico, refletindo sobre texto enquanto também ensina seus leitores. Logo, os três autores - Bronckart (2012), Charaudeau (2012) e Guedes (2009) - direcionam seus olhares para o texto, mas com diferentes objetivos.

No quarto capítulo, a autora disserta sobre os textos dos alunos do Ensino Médio em 2014, os mesmos que, em 2012, estavam na oitava série participando dos debates. Os alunos escreviam seus textos e realizavam a leitura pública das produções em aula a partir das atitudes dissertativas também elencadas por Guedes (2009): análise, comparação, classificação e definição, estudadas durante três trimestres. Cada trimestre priorizou uma atitude dissertativa - exceto a comparação,

\footnotetext{
${ }^{5} \mathrm{~A}$ autora faz uma criteriosa distinção entre concretude e objetividade em sua obra, a fim de salientar que os conceitos são, de fato, diferentes. Sua opção em analisá-la dentro da concretude foi em razão da dificuldade de abstração desses conceitos por parte dos estudantes, pois foram planejados por Guedes (2009) para alunos do Ensino Superior, e não da Educação Básica.

${ }^{6}$ Jean-Paul Bronckart é professor de Didática de Línguas na Faculdade de Psicologia e Ciências da Educação na Universidade de Genebra. Desenvolveu diversos programas de pesquisa.

7 Patrick Charaudeau é um linguista francês, especialista em Análise do Discurso, fundador da Teoria Semiolinguística de Análise do Discurso.
}

https://periodicos.unifap.br/index.php/letras

Macapá, v. 9, n. 4, $2^{\circ}$ sem., 2019 
pois, segundo a reflexão apresentada pela autora, já estava inserida nas demais. Os temas dos textos eram livres desde que estivessem dentro das propostas que guiavam a prática. Em cada uma dessas atitudes dissertativas, as escritas e reescritas dos alunos foram analisadas e refletidas pela professora-pesquisadora e pelos alunos, em busca das qualidades discursivas de Guedes (2009), a partir da discussão realizada para orientação da reescrita dos textos. Assim, esse capítulo conta com uma análise interpretativa de vinte textos de alunos, entre os quais estão as primeiras versões e também as suas reescritas. De acordo com as conclusões de Netto a partir de sua análise dos textos dos alunos, as reescritas deles evidenciaram a busca da significação de termos utilizados nas suas primeiras versões e a reorganização das ideias para melhor esclarecer ao leitor os que os textos estavam se propondo a dizerem (NETTO, 2017, p. 176-177).

Diante das escritas e reescritas dos alunos, a análise feita por Netto é completamente discursiva, enriquecendo sua pesquisa e indo ao encontro do que a autora propõe com seu aporte teórico - baseado em Bronckart (2012), Charaudeau (2012) e Guedes (2009). Consiste, então, em tal encontro da autora com o seu aporte teórico, o intuito de, com a proposta de Guedes (2009), que está no âmbito de uma abordagem dialógica de estudos da linguagem, relacionar essa proposta com as ideias de Bronckart (2012) e Charaudeau (2012). Bronckart (2012) e Charaudeau (2012) também apresentam estudos sobre textos que se caracterizam enquanto uma abordagem dialógica da linguagem, mas com percepções do trabalho com gêneros do discurso também. O que a autora explica, então, é que, embora Guedes (2009) não proponha um estudo de produção de gêneros do discurso, mas de textos, esses textos podem ser pensados no âmbito dos gêneros do discurso quando o texto estiver em sua construção.

Há, ainda, uma grande preocupação de Netto no revisar: encontrar o sentido daquilo que os alunos dizem através das qualidades discursivas, minimizando também erros gramaticais de qualquer tipo. Durante todas as revisões - eu opto pela palavra revisão ao invés de correção por acreditar que se aproxime mais da postura docente e orientadora de Netto -, a autora sugere melhoras necessárias com vistas a um texto discursivamente claro, melhoras relacionadas, por exemplo, à organização das ideias expostas no texto, à apresentação do assunto, aos ganchos e aos esclarecimentos dos exemplos; enfim, às características das qualidades discursivas formuladas por Guedes (2009). Dessa maneira, Netto se mostra coerente com as ideias que segue ao longo de toda a sua obra.

Nas suas considerações finais, Netto conclui que todo o caminho realizado durante a sua pesquisa gerou um aprendizado como professora e como pesquisadora e, principalmente, aprendizado aos alunos - que passaram, inclusive, a utilizar a palavra concretude com propriedade até mesmo em momentos inesperados. A autora termina a sua escrita questionando qual o papel do professor e como ele é capaz de transformar a realidade em que vivemos. Logo em seguida, é ela quem responde: RESISTIR. É preciso resistir às adversidades, como as associações que atrelam o ensino do texto unicamente à preparação para o vestibular, por exemplo. O papel do professor, assim entendemos, é resistir a tais limitações a fim de praticar outras propostas de ensino e aprendizagem.

Em linhas gerais, Produção Textual - formulando e reformulando práticas de sala de aula (2017) constitui-se enquanto uma obra que exemplifica a teoria e a prática de uma professora que se doa ao que quer ensinar - ao pensar em diferentes maneiras que saiam da convenção escolar a ponto de criar um projeto de debates -, bem como de uma pesquisadora que tenta quebrar os paradigmas ainda atuais acerca do que é o aprender sobre produção textual na educação. Acima de tudo isso, o principal aprendizado que essa obra nos traz é a de que existem caminhos para a aula de texto que diferem dos já tão conhecidos e fracassados modos de colocar todas as escritas escolares em um só formato.

Netto cumpriu sua missão como professora ao ensinar seus alunos quais são as maneiras de escrever melhor e de compreender as estruturas gramaticais da língua escrita sem que, para isso, ela precisasse adotar uma correção que pune ou avaliações com questões descontextualizadas que apenas servem para que o aluno decore regras que logo depois serão esquecidas. Com isso, 
mostrou-se também uma grande pesquisadora que faz da sua questão-problema, decorrente de situações práticas de sala de aula, um propósito de estudo. Serve, então, esse livro, como combustível para que outros professores busquem uma realidade mais reflexiva em sala de aula, o que proporcionará ganhos, consequentemente, aos alunos, pois a sala de aula é o espaço de uma grande agência de letramento e, sobretudo, de reflexão. Repensar os conteúdos dados em sala de aula, assim sendo, é primordial tanto para aquele que ensina quanto para aqueles que aprendem. Em outros termos, no trabalho com texto, a autora mostra a necessidade de:

- pensar e repensar as práticas de sala de aula;

- ampliar as abordagens acerca do ensino textual, especificamente, aproximando desse ensino assuntos que fazem parte da vida dos alunos;

- diversificar caminhos, como nos debates propostos, até o aprimoramento da escrita dos alunos;

- embora não tenha sido apresentada uma fórmula pronta de ensino, há um esboço de tentativas responsáveis e constantes a fim de reconfigurar o ensino e a aprendizagem textual para melhor.

Como mestranda em Letras, em minhas pesquisas e estágios, eu vejo ainda o quanto há professores que, apesar de terem estudado a fim de pensar sobre a língua ao invés de ensinar regras gramaticais descontextualizadas, preferem não lutar mais pela sua liberdade ao lecionar quando se deparam com situações sistematizadas de ensino. Esse livro, então, serve de incentivo também para aqueles que são professores ainda em formação. Por fim, acentuo a atenção com que Netto dedicou-se a escrever sua obra: um texto fluido e fácil de ler - consequência de uma autora que muito pensou e preocupou-se com o seu leitor. Também por isso, esse livro é um convite a todos que tenham interesse por uma nova reflexão de ensino de produção textual em uma leitura delicada e prazerosa.

\section{REFERÊNCIAS}

BAKHTIN, M. Marxismo e filosofia da linguagem. 13ª edição. São Paulo: Hucitec, 2009.

BRONCKART, J. P. Atividades de linguagens, textos e discursos: por um interacionismo sociodiscursivo. $2^{a}$ edição. São Paulo: Educ. 2012. (320p.)

CHARAUDEAU, P. Linguagem e discurso: modos de organização. $2^{a}$ edição. São Paulo: Contexto, 2012. (273 p.)

GUEDES, P. C. Da redação à produção textual: o ensino da escrita. São Paulo: Parábola, 2009. (342 p.)

NETTO, D. F. Produção Textual - formulando e reformulando práticas de sala. São Paulo: Paco Editorial, 2017. (186 p.)

Recebido em: 12/07/2019

Aprovado em: 20/08/2019 